Dhaka Univ. J. Biol. Sci. 22(2): 127-134, 2013 (July)

\title{
HAEMATOLOGY OF AIR BREATHING MUD EEL, MONOPTERUS CUCHIA (HAMILTON, 1822) OF MYMENSINGH AND KISHOREGANJ DISTRICTS OF BANGLADESH
}

\author{
A.F.M. Nazmus Salehin, Shankar Chandra Mandal* and Anwar Hossain \\ Department of Fisheries, University of Dhaka, Dhaka-1000, Bangladesh
}

Key words: Haematological profile, Air breathing mud eel, Monopterus cuchia, Haematocrit

\begin{abstract}
Haematological profile of air breathing mud eel, Monopterus cuchia (Hamilton) from Mymensinghh and Kishoreganj were determined in the present study. Erythrocytes, lymphocytes, monocytes, neutrophils, eosinophils and platelet were evaluated. Significantly higher $(\mathrm{p}<0.05)$ haemoglobin $(\mathrm{Hb})$ concentration was found in air breathing mud eel of Kishoreganj than that of Mymensinghh area. The haematocrit (HCT), erythrocyte sedimentation rate (ESR), total red blood cells (TRBC), mean corpuscular volume (MCV), mean corpuscular haemoglobin (MCH), mean corpuscular haemoglobin concentration (MCHC), total white blood cells (TWBC), lymphocytes, neutrophils, monocytes, eosinophils did not show any significant difference. Findings of the present study showed little variation of haematological profile in air breathing mud eel sampled from Mymensinghh and Kishoreganj.
\end{abstract}

\section{Introduction}

Freshwater air breathing mud eel, Monopterus cuchia (Hamilton) locally known as cuchia belongs to family Synbranchidae of the order Synbranchiformes. It commonly occurs in swamps, mud-holes, boro-paddy fields and ponds of Bangladesh, India, Pakistan and Sri Lanka( ${ }^{(1)}$. Cuchia is a freshwater and brackishwater fish; found in shallow, well vegetated waters and mud which inhabits plenty in mud holes in shallow beels and boro paddy field of Sylhet, Mymensinghh and Tangail districts(2). It has also been recorded from Chalan beel of Bangladesh(3).

The fish is only consumed by the tribal people in Bangladesh; however it is commercially important due to its high demand for export. Its blood is sometimes recommended by local kobiraj. The local fishermen have reported that the population of this freshwater eel is declining from the natural water bodies due to heavy fishing pressure and unfriendly environments. There is no system of artificial propagation developed to save this freshwater eel from extinction. Earlier a few isolated studies have been carried out by researchers ${ }^{(4)}$.

*Author for correspondence: <shankar@univdhaka.edu>. 
Very few literatures are available on cuchia of Bangladesh. Haematological parameters of cuchia in Bangladesh water body is not yet evaluated properly. Present study was thus conducted to determine the concentration of different haematological parameters and to evaluate whether there has been any variation due to different habitats.

\section{Materials and Methods}

Air breathing mud eel, cuchia, Monopterus cuchia (Hamilton) from two districts of Bangladesh, namely Mymensingh $(170.00 \pm 14.72 \mathrm{~g}, 46.00 \pm 0.91 \mathrm{~cm})$ and Kishoreganj $(178.75 \pm 10.87 \mathrm{~g}, 46.50 \pm 0.65 \mathrm{~cm})$ were used as experimental animals. A total of 30 fish were sacrificed ( 15 from each habitat) for estimation of haematological parameters. The experiment was done in triplicate. The experiment was conducted in diagnostic center.

The experimental variables were the level of blood parameters such as haemoglobin $(\mathrm{Hb})$, haematocrit $(\mathrm{HCT})$, erythrocyte sedimentation rate (ESR), total red blood cells (TRBC), mean corpuscular volume (MCV), mean corpuscular haemoglobin (MCH), mean corpuscular haemoglobin concentration (MCHC), total white blood cells (TWBC), lymphocytes, neutrophils, monocytes, eosinophils and platelets.

Blood samples were obtained by severing the caudal peduncle. The fish was taken on a tray and the head was covered by a black net because it was too slimy to hold on by a simple cloth. A sample of $2.5 \mathrm{ml}$ blood was collected by using $10 \mathrm{ml}$ plastic syringe and put in test tube containing K3 EDTA solution which was used as anticoagulant. The blood samples were collected rapidly to avoid the rapid coagulation of blood. Blood parameters were estimated by SYSMEX-XT-1800i Auto Haematology Analyzer. This machine analyzes blood parameters using three detector blocks and two kinds of reagents. For analyzing haemoglobin, oxyhaemoglobin method was applied.

The microhaematocrit method was used to determine the haematocrit ${ }^{(5)}$. Haemoglobin concentration was measured by the cyanmethaemoglobin method (6). Red and white blood cell counts were counted under light microscope with an improved Neubauer haemocytometer. Differential leucocyte counts were made from Leishman/Giemsa stained blood smears. Erythrocyte sedimentation rate was determined with microhaematocrit tubes filled with blood and allowed to stand for $60 \mathrm{~min}$.

Some variables were calculated using the data obtained directly from above mentioned methods ${ }^{(7)}$. The variables were: Mean corpuscular volume $(\mathrm{MCV}), \mathrm{fl}=\mathrm{HCT}$ $(\%) R B C\left(\times 10^{6} / \mu \mathrm{l}\right) \times 10$; Mean corpuscular haemoglobin $(\mathrm{MCH}), \mathrm{pg}=\mathrm{Hb}(\mathrm{g} / \mathrm{dl}) \operatorname{RBC}(\times$ $\left.10^{6} / \mu \mathrm{l}\right) \times 10$; Mean corpuscular haemoglobin concentration $(\mathrm{MCHC}), \mathrm{gd} \Lambda=\mathrm{Hb}(\mathrm{g} / \mathrm{dl}) /$ $\mathrm{HCT}(\%) \times 10$. 
Data were expressed as mean \pm standard error of means. Differences between sources were compared using t-test. Statistical software SPSS version 17 was used to analyze data with the levels of significance at $p<0.05$.

\section{Results and Discussions}

$\mathrm{Hb}$ concentration detected in cuchia sampled from Kishoreganj $(19.58 \pm 0.06 \mathrm{~g} / \mathrm{dl})$ was significantly higher than that of Mymensingh (18.64 $\pm 0.12 \mathrm{~g} / \mathrm{dl})$ (Fig. 1). However, $\mathrm{Hb}$ concentration observed in cuchia of both sources was higher than findings of other authors in many fishes $\left(14.24 \pm 0.66 \mathrm{~g} / \mathrm{dl}\right.$ in C. batrachus by Naser and Liza ${ }^{(8)}$. The functional properties of fish haemoglobin are strongly influenced by environmental conditions $^{(9)}$. Generally hemoglobin is a compound of globin with hematin. A molecule of hematin contains 1 atom of iron. This atom of iron enables hemoglobin to carry oxygen in large amounts ${ }^{(10)}$. So the higher $\mathrm{Hb}$ concentrations in cuchia of both sources may be due to the lower oxygen level of water body.

Percentage HCT found in cuchia obtained from Mymensingh $(54.11 \pm 0.25)$ was similar to that of Kishoreganj (53.98 \pm 0.25 ; Fig. 2). Blood viscosity is primarily a function of HCT, increasing exponentially as HCT increases from near zero up to levels as high as $70 \%$ in teleosts ${ }^{(11)}$. HCT level of both sources were similar might be due to same environmental conditions at both places. It has been observed that blood parameters such as haematocrit, haemoglobin concentration and RBC count are related to environmental factors such as water temperature and salinity ${ }^{(12)}$.
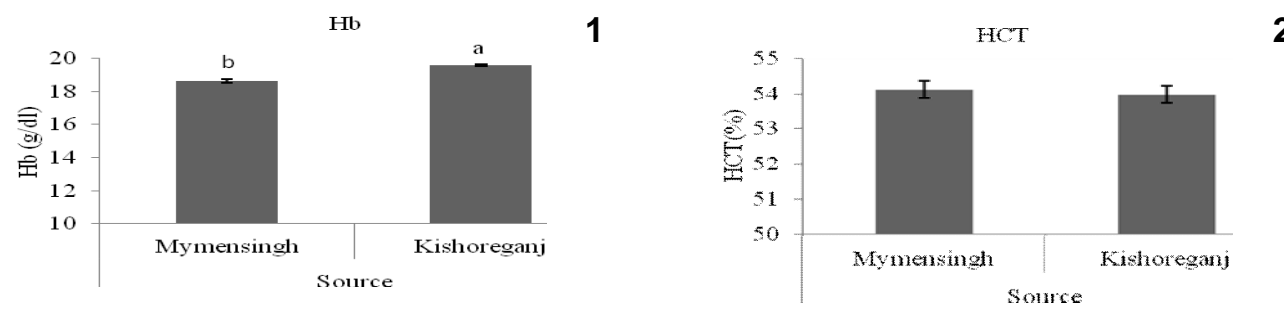

2

Figs 1, 2: 1 Haemoglobin $(\mathrm{Hb})$ concentration of cuchia, M. cuchia sampled from Mymensingh and Kishoreganj. Bars (mean \pm SEM) with same color different letters are significantly different $(\mathrm{p}<$ 0.05). 2. HCT percentage of cuchia, M. cuchia of Mymensingh and Kishoreganj. Bars (mean \pm SEM) with same color show no significant difference $(\mathrm{p}<0.05)$.

ESR detected in cuchia sampled from Mymensingh $\left(6.50 \pm 0.50 \mathrm{~mm}\right.$ in $\left.1^{\text {st }} \mathrm{hr}\right)$ and Kishoreganj ( $6.00 \pm 0 \mathrm{~mm}$ in $1^{\text {st }} \mathrm{hr}$ ) was similar (Fig. 3). Normal range of ESR level (less than $10 \mathrm{~mm}$ in $1^{\text {st }} \mathrm{hr}$ ) indicates the healthy physiological condition of the fish as ESR is used as an indicator of health of fish (13). Similar ESR level in Amphipnous cuchia was found elsewhere ${ }^{(14)}$. 
Similar total RBC was detected in cuchia sampled from both Mymensingh (3.89 \pm $0.04 \mathrm{~m} / \mathrm{cumm}$ ) and Kishoreganj $(3.88 \pm 0.03 \mathrm{~m} / \mathrm{cumm})$ (Fig. 4). Similar TRBC of two sources indicates the similar physiological activities of the fish. High levels of TRBC in cuchia show the highly air breathing characteristics through carrying oxygen into the blood. The RBC counts of some air breathing fishes were $4.0-4.9 \mathrm{~m} / \mathrm{cumm}$ in male and $3.8-5.9 \mathrm{~m} / \mathrm{cumm}$ in female of Anabas testudineus ${ }^{(15)}$ is in agreement with the findings of the present study.

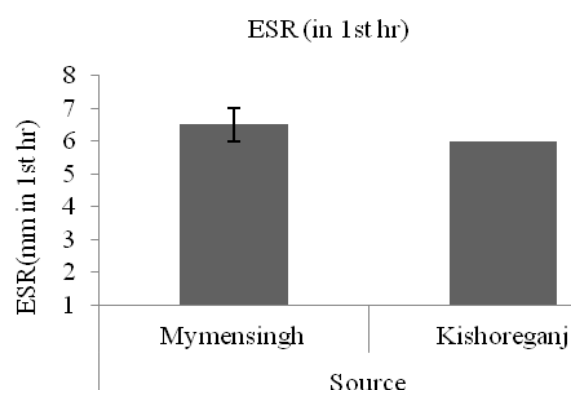

3

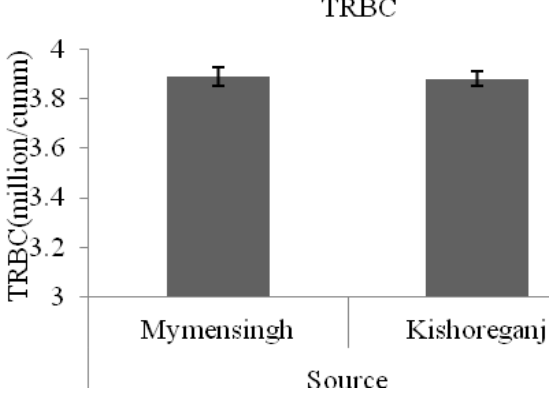

Figs 3, 4: 3. Erythrocyte sedimentation rate (ESR) of cuchia, M. cuchia obtained from Mymensingh and Kishoreganj. Bars (mean \pm SEM) with same color indicate no significant difference $(p<0.05)$. 4. Total red blood cells (TRBC) of cuchia, M. cuchia sampled from Mymensingh and Kishoreganj. Bars (mean \pm SEM) with same color denote no significant difference $(\mathrm{p}<0.05)$.

No significant difference of MCV was found in cuchia taken from Mymensingh and Kishoreganj ( $\mathrm{p}$ <0.05). MCV detected in cuchia sampled from Mymensingh was $139.00 \pm$ $2.00 \mathrm{fl}$ and and that of Kishoreganj was $139.50 \pm 1.50 \mathrm{fl}$ (Fig. 5). Moderate MCV values found in the present study may be due to similar condition of the RBC and HCT content in fish and due to the similar condition of the environmental factors in both places. Some MCV values found in different species are: $49.42 \pm 1.87 \mathrm{fl}$ in male and $50.91 \pm 0.42 \mathrm{fl}$ in female Oreochromis niloticus ${ }^{(16)}$. Arnaudova et al. found MCV values $292.5 \pm 64.1 \mathrm{fL}$ in summer and $288.2 \pm 25.6 \mathrm{fl}$ in winter in Albarnus alburnus (17).

$\mathrm{MCH}$ detected in cuchia from Mymensingh (48.00 $\pm 1.00 \mathrm{pg})$ and Kishoreganj (50.50 \pm $0.50 \mathrm{pg}$ ) was not significantly different (Fig. 6). This similar $\mathrm{MCH}$ levels in both sources may be due to similar environmental conditions in both places. Some $\mathrm{MCH}$ level showed by some scientists are: $83.2 \pm 20.4 \mathrm{pg} / \mathrm{kell}$ in summer and $77.0 \pm 13.4 \mathrm{pg} / \mathrm{kell}$ in winter in Albarnus alburnus(17) which is different from the findings of the present study might be due to variation of species.

Levels of MCHC found in cuchia from sources of Mymensingh $(34.50 \pm 0.50 \mathrm{~g} / \mathrm{dl})$ and Kishoreganj $(36.50 \pm 0.5 \mathrm{~g} / \mathrm{dl})$ was not significantly different (Fig. 7). Though the amount of $\mathrm{Hb}$ was different, $\mathrm{MCHC}$ level of both places showed no significant difference which indicates the same blood contents of two sources. MCHC values found in the blood of 
cuchia are supported by some authors as $34.62 \pm 3.23 \mathrm{~g} / \mathrm{dl}$ in male and $32.62 \pm 3.25 \mathrm{~g} / \mathrm{dl}$ in female O. niloticus ${ }^{(16)}$.

Similar count of TWBC was detected in cuchia sampled from both Mymensingh (11850 \pm 350 /cumm) and Kishoreganj (11800 \pm 100 /cumm) (Fig. 8). The amount found in both places was not very high which indicated the lower infections of pathogens in both places, because the amount of WBC increases with the increase in infections by pathogenic organisms. Another reason for lower WBC level might be their benthic habitat in the water body(6). Goel et al. found 12400 to $31400 / \mathrm{cumm}$ TWBC in seven different species of fishes which are in the range of the findings of the current study ${ }^{(18)}$.
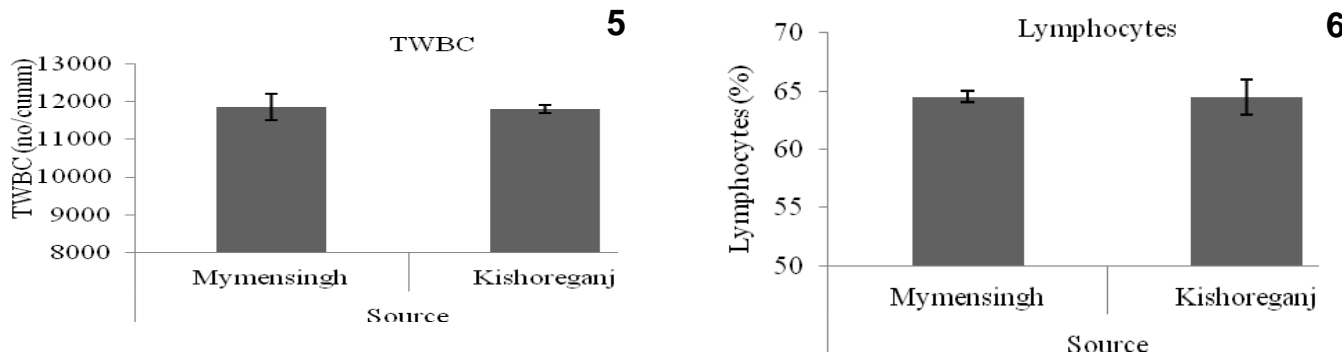

Figs 5, 6: 5. Mean corpuscular volume (MCV) of cuchia, M. cuchia observed in Mymensingh and Kishoreganj. Bars (mean \pm SEM) with same color show no significant difference $(\mathrm{p}<0.05)$. 6. Mean corpuscular haemoglobin (MCH) of cuchia, M. cuchia of Mymensingh and Kishoreganj. Bars (mean \pm SEM) with same color denote no significant difference $(\mathrm{p}<0.05)$.

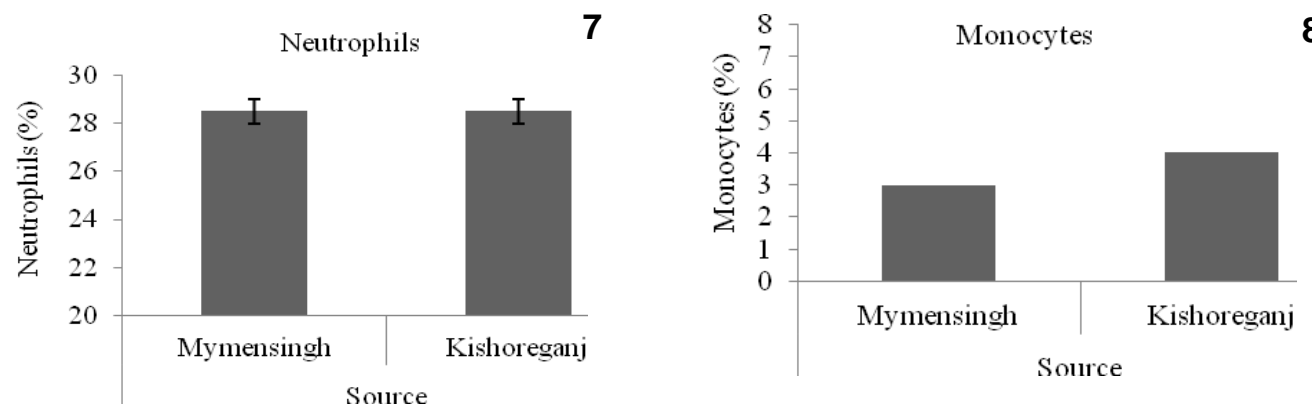

Figs 7, 8: 7. Mean corpuscular haemoglobin Concentration (MCHC) levels of cuchia, M. cuchia of Mymensingh and Kishoreganj. Bars (mean \pm SEM) with same color indicate no significant difference $(\mathrm{p}<0.05)$. 8. Total white blood cells $($ TWBC) of cuchia, M. cuchia collected from Mymensingh and Kishoreganj. Bars (mean \pm SEM) with same color show no significant difference $(\mathrm{p}<0.05)$.

No significant difference in percentage of lymphocytes was found in cuchia collected from Mymensingh $(64.50 \pm 0.50 \%)$ and Kishoreganj $(64.50 \pm 1.50 \%$, Fig. 9). Similar lymphocytes level indicates the similar breeding of both sources of fish because the level 
decreases in male and increases in female during breeding season ${ }^{(14)}$. Ugwem et al.(16) observed $69.67 \pm 0.92 \%$ lymphocytes in male and $60.18 \pm 3.86 \%$ in female Oreochromis niloticus which support the findings of the present study.

Similar level of neutrophils (\%) was found in cuchia collected from Mymensingh $(28.50 \pm 0.50 \%)$ and Kishoreganj $(28.50 \pm 0.50 \%$, Fig. 10). Observed neutrophils level was similar in both places due to the healthy and same natural conditions of the environment because neutrophils are very sensitive to the environmental change. Among the WBCs neutrophil is very important environmental indicator. $0-25 \%$ neutrophils were found in brown trout while $36.94 \pm 1.06 \%$ in male and $36.42 \pm 3.59 \%$ in female O. niloticus ${ }^{(16)}$.
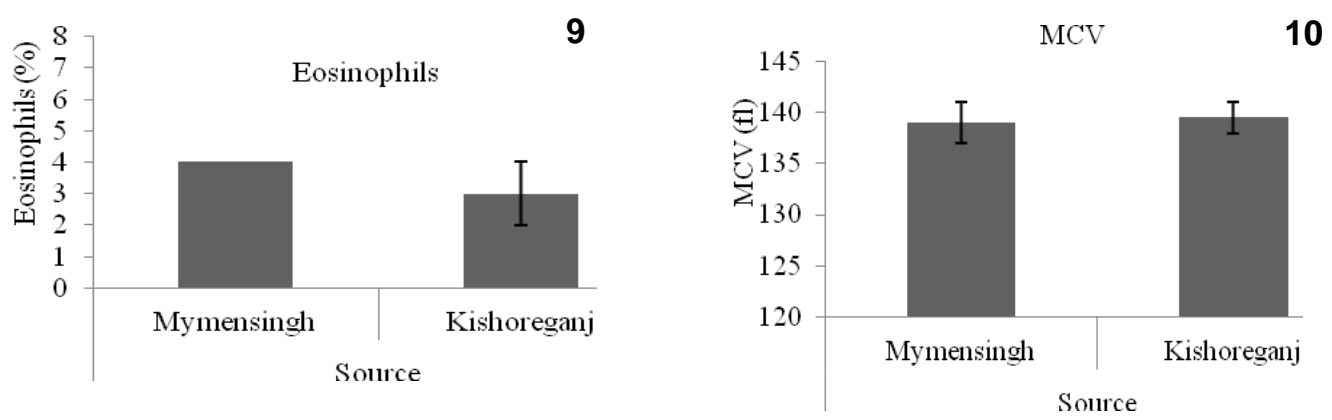

Figs 9, 10: 9. Lymphocytes percentage of cuchia, M. cuchia taken from Mymensingh and Kishoreganj. Bars (mean \pm SEM) with same color show no significant difference $(\mathrm{p}<0.05)$. 10. Neutrophils percentage of cuchia, M. cuchia of Mymensingh and Kishoreganj. Bars (mean \pm SEM) with same color indicate no significant difference $(\mathrm{p}<0.05)$.

Percentage of monocytes in cuchia taken from Mymensingh $(3.00 \pm 0 \%)$ and Kishoreganj $(4.00 \pm 0 \%)$ were similar (Fig. 11). Similar monocytes levels indicate the similar natural conditions of both places. These natural environments possess same level of leucocytes in both places. Naser and Liza ${ }^{(8)}$ found monocytes level at an average of 4.89 $\pm 1.94 \%$ in Clarias batrachus, $3.37 \pm 0.14 \%$ in male Oreochromis niloticus by Ugwem et al.(16).

Eosinophils percentage of cuchia from Mymensingh $(4.00 \pm 0.0 \%)$ and Kishoreganj $(3.00 \pm 1.00 \%)$ had no significant difference while compared (Fig. 12). Though the presence of eosinophils in fish was not confirmed by many scientists, present study confirmed the presence of eosinophils in fishes. Level of eosinophils in cuchia was in the range of $2-4 \%$. Khan and Qayuum found ${ }^{(19)} 14.1 \%$ eosinophils in Ophicaphalus striatus and $7.6 \%$ in Clarias batrachus which were very much higher than that of cuchia found in the present study.

Similar counts of platelets were found in cuchia taken from Mymensingh (315000 \pm 5000 /cumm) and Kishoreganj (305000 $\pm 15000 / \mathrm{cumm}$ ) (Fig. 13). Higher level of platelets found in cuchia indicates the higher blood clotting capacity. Similar result was detected

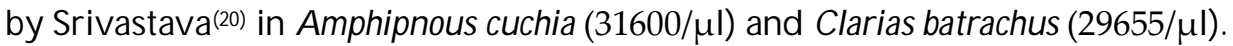



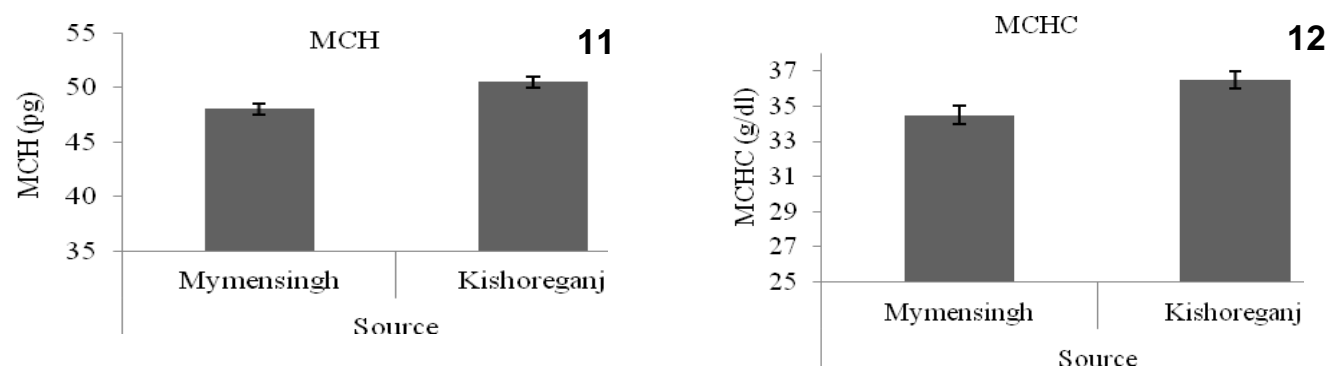

Figs 11, 12: 11. Percentage of monocytes of cuchia, M. cuchia obtained from Mymensingh and Kishoreganj. Bars (mean \pm SEM) with same color show no significant difference $(\mathrm{p}<0.05)$. 12. Percentage of eosinophils in cuchia, $M$ cuchia obtained from two different sources Mymensingh and Kishoreganj. Bars (mean \pm SEM) with same color denote no significant difference $(\mathrm{p}<0.05)$.

Platelet

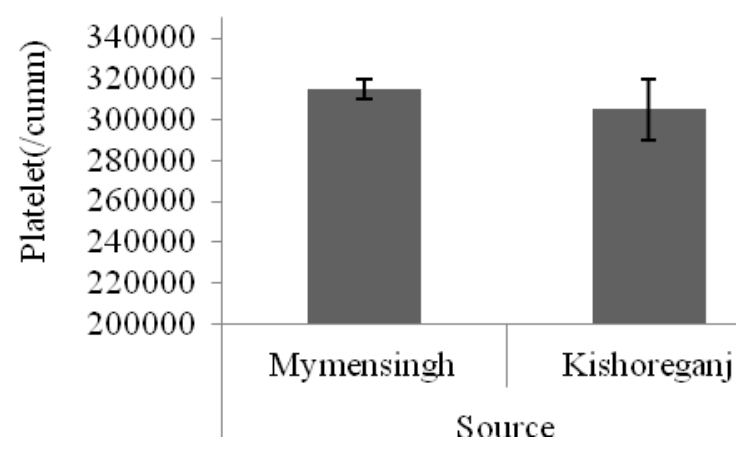

Fig. 13. Amount of platelets in cuchia, M. cuchia collected from Mymensingh and Kishoreganj. Bars (mean \pm SEM) with same color are not significantly different $(p<0.05)$.

The current study showed significant difference in Haemoglobin concentration in cuchia of Mymensingh and Kishoreganj. Haematocrit (HCT), Erythrocyte Sedimentation Rate (ESR), Total Red Blood Cells (TRBC), Mean Corpuscular Volume (MCV), Mean Corpuscular Haemoglobin (MCH), Mean Corpuscular Haemoglobin Concentration (MCHC), Total White Blood Cells (TWBC), Lymphocytes, Neutrophils, Monocytes, Eosinophils and Platelets showed no significant difference. This study indicates the haematological parameters of cuchia found very little differences with the changes of habitats.

\section{References}

1. Rahman AKA 1989. Freshwater Fishes of Bangladesh, 1st edition, Zoological Society of Bangladesh, Department of Zoology, University of Dhaka, Dhaka-1000. pp. 50-51.

2. Rahman AKA 2005. Freshwater Fishes of Bangladesh, 2nd edition, Zoological Society of Bangladesh, Department of Zoology, University of Dhaka, Dhaka-1000, pp. 65-66. 
3. Galib SM, MA Samad, ABM Mohsin, FA Flowra and MT Alam 2009. Present Status of Fishes in the Chalan Beel - the Largest Beel (Wetland) of Bangladesh. Int. J. Ani. Fish. Sci. 2:214-218.

4. Hughes GM, BR Singh and RN Thakur 1974. Areas of the air- breathing surfaces of Amphipnous cuchia (Ham.). Proc. atn. Acad. Sci. India 40: 379- 292.

5. Snieszko SF (1960). Microhaematocrit as a tool in fishery research and management. U. S. Wildl. Serv. Sci. Rep. Fish. 341: 15-23.

6. Larsson AML, Johansson-Sjobeck and R Fange 1976. Comparative study of some haematological and biochemical blood parameters in fishes from Skagerrak. J. Fish. Biol. 9: 425-440.

7. Dacie JV and SM Lewis 2001. Practical Haematology 9th ed. Churchill Livingstone, London. pp: 633.

8. Naser MN and MA Liza 2007. Some haematological parameters of adult magur, Clarias batrachus (Linnaeus, 1758) from a culture pond of Dhaka, Bangladesh. Bangladesh J. Zool. 35: 71-80.

9. Johansen K and RE Weber 1975. On the adaptability of hemoglobin function to environmental conditions. In: Perspectives in Experimental Biology, vol. I, Zoology (ed. P. Spencer Davis). Oxford: Pergamon Press.

10. Barcroft J 1928. The respiratory function of the blood, Cambridge, 2nd ed., pp. 2.

11. Graham MS and GL Fletcher 1983. Blood plasma viscosity of winter flounder: Influence of temperature, red cell concentration, and shear rate. Can. J. Zool. 61: 2344-2350.

12. Graham JB 1997. Air-breathing Fishes: Evolution, diversity, and adaptation. Academic Press, San Diego.

13. Khaleque KA 1987. Practical Pathology. 7th ed. Polwel Printing Press, Dhaka, Bangladesh. p. 623.

14. Mishra N, JS Pandey, Datta, JK Munshi and BR Singh 1977. Haematological parameters of an air breathing mud eel, Amphipnous cuchia (Ham.) (Amphipnoidae: Pisces). J. Fish-Biol. 10: 567-573.

15. Banarjee V 1966. A note on the haematological studies of Anabas testudineus (Bloch). Sci. and Cult. 32: 326-327.

16. Ugwem U, AA Gabriel Ojo and E Funkeye 2011. Haematological responses of Wild Nile Tilapia Oreochromis niloticus after acclimation to captivity. Jordan J. Biological Sci. 4: 225230.

17. Arnaudova D, A Arnaudov and E Tomava 2008. Selected haematological indices of freshwater fish from Student Kladenetsh reservoir. Bul. J. Agr. Sci. 14: 244-250.

18. Goel KA, BP Mishra, K Gupta and S Wadhaw 1984. A comparative Haematological study of few freshwater teleosts. Ind. J. Fish 31: 108-112.

19. Khan SH and AQ Qayuum 1969. Differential blood cell count of four freshwater air breathing fishes. Proc. Ind. Acd. Sci 69: 29-72.

20. Srivastava AK 1969. Studies on the haematology of certain freshwater teleost.III. Thrombocytes and clotting time. Anat. Anz. 124: 368-374.

(Manuscript received on 13 April, 2013; revised on 8 June, 2013) 